\title{
Pregnancy Outcome in Women with Heart Disease in a Tertiary Care Centre in Kolkata, India
}

\author{
Mihir Kumar Sarkar ${ }^{1}$, Arindam Halder ${ }^{2}$ \\ 1, 2 Department of Obstetrics Gynaecology and Child Health, \\ Chittaranjan Seva Sadan College, Kolkata, West Bengal, India.
}

\section{ABSTRACT}

\section{BACKGROUND}

The incidence of cardiac lesions is less than $1 \%$ amongst hospital deliveries. The commonest cardiac lesion is of rheumatic origin followed by the congenital ones. Heart diseases have a significant impact on maternal and perinatal morbidity and mortality. The purpose of the study was to find out the specific heart lesion in pregnancy in a particular demographic area and evaluate the maternal and perinatal outcome.

\section{METHODS}

This was a two-year retrospective observational study done by reviewing the records of all the mothers with heart diseases admitted for pregnancy from April 2016 to March 2018.

\section{RESULTS}

The study included 42 patients. The majority of heart lesions was mitral stenosis of rheumatic origin. Prophylactic forceps in second stage of labour was the major method of delivery. As far as the perinatal outcome is concerned, low birth weight and prematurity were the major problem in the babies born to these mothers.

\section{CONCLUSIONS}

With advances in medical care and surgical approach, the obstetricians should be prepared to manage an increasing number of women with heart disease during pregnancy. A combined multidisciplinary care is essential in managing these cases.

\section{KEY WORDS}

Rheumatic Heart Disease, Congenital Heart Disease, Cardiac Failure, Forceps Delivery, Prematurity
Corresponding Author: Dr. Arindam Halder, Suravi, Udayan Housing Complex, Pratapgarh, Narendrapour, Kolkata-700103, West Bengal, India. E-mail: halderarindam1978@gmail.com

DOI: $10.14260 / \mathrm{jemds} / 2021 / 276$

How to Cite This Article: Sarkar MK, Halder A. Pregnancy outcome in women with heart disease in a tertiary care centre in Kolkata, India. J Evolution Med Dent Sci 2021;10(18):1309-1313, DOI: 10.14260/jemds/2021/276

Submission 18-12-2020,

Peer Review 25-02-2021,

Acceptance 05-03-2021,

Published 03-05-2021.

Copyright (C) 2021 Mihir Kumar Sarkar et al. This is an open access article distributed under Creative Commons Attribution License [Attribution 4.0 International (CC $B Y 4.0)]$ 


\section{BACKGROUND}

Vast improvement in the medical care and advances in the surgical techniques over the past few decades have enabled an increasing number of women with congenital and acquired childhood heart disease surviving into childbearing age and opting for pregnancy, thus causing a major concern for the obstetrician. Although the maternal mortality rate in these patients has decreased from $2.7 \%$ to $5 \%$ according to various reports, 1,2,3,4 the morbidity in this high-risk group is still a problem. The increased morbidity is related to immense haemodynamic alteration in the mother beginning as early as five weeks of gestation. ${ }^{5}$ The hormone mediated increase in blood volume, red cell mass and heart rate results in increased cardiac output by 30 - $50 \% .{ }^{6}$ Stroke volume begins to increase at 5 weeks of gestation, peaks at 31 weeks and then gradually declines till term. ${ }^{6}$ There is also a decrease in the peripheral vascular resistance due to circulating prostaglandins, hormones and low resistance vascular bed in placenta. During labour and delivery, the supine position, uterine contractions, anxiety and pain increase the risk of maternal cardiovascular and haemodynamic decompensation. ${ }^{7,8}$ This is the reason why these women with cardiac problem need special attention and multidisciplinary care by cardiologist and obstetricians throughout pregnancy and especially during labour and delivery. Majority of women start labour spontaneously and deliver vaginally. Elective induction of labour may be needed in few cases. This depends on the availability of multidisciplinary team members, to help the woman during the peripartum period.

The present study was conducted to -

1. determine the specific heart lesions.

2. evaluate maternal and perinatal outcome.

\section{METHODS}

This was a retrospective observational study that was conducted in the Department of Obstetrics \& Gynaecology, Chittaranjan Seva Sadan, Kolkata from April 2016 to March 2018. Permission from hospital ethical committee was taken and informed consent was properly documented.

All the cases of heart disease with pregnancy admitted during the aforesaid period irrespective of age, parity and duration of gestation were included. Heart disease with severe anaemia, severe hypertension, and placenta praevia were excluded from the study.

All the cases were subjected to history taking with special emphasis to age, parity, previous pregnancy and labour events, specific complains related to cardiovascular system and their relationship with physical activity, medications and prior surgical intervention. A thorough general, cardiac and obstetric examination was performed next. Apart from routine antenatal investigations, the special investigations done in each case were - electrocardiogram (ECG), echocardiography and ultrasound sonography (USG).

The events during ante partum, intra partum, postpartum period was recorded and the newborn was examined at birth for Apgar score, birth weight and congenital anomaly. A note was kept regarding the first 7 days of neonatal period.

\section{Statistical Analysis}

Data analyses were carried out using Statistical Product Service Solution (SPSS) IBM version 21.0. Descriptive statistics such as mean, standard deviation and range values were computed for quantitative variables. Frequency data across categories were compared using chi-square / Fishers exact test as appropriate.

\section{RESULTS}

The study included 42 patients. Age of the patients shows that majority of the women were aged between 18 - 30 (88.09\%) whereas only $4(9.52 \%)$ were above 30 years and 1 patient (2.3\%) was below 18 years of age.

\begin{tabular}{|c|c|c|}
\hline Age & No & $\%$ \\
\hline$<18$ years & 1 & $2.3 \%$ \\
\hline $18-30$ years & 37 & $88.09 \%$ \\
\hline$>30$ years & 4 & $9.52 \%$ \\
\hline Gravida & No & $\%$ \\
\hline G1 & 27 & $64.28 \%$ \\
\hline G2 & 13 & $30.95 \%$ \\
\hline G3 & 2 & $4.76 \%$ \\
\hline G4 \& above & Nil & $0.00 \%$ \\
\hline Type & No & $\%$ \\
\hline Rheumatic & 30 & $71.43 \%$ \\
\hline MS & 19 & $63.33 \%$ \\
\hline MR & 0 & $00.00 \%$ \\
\hline $\mathrm{MS}+\mathrm{MR}$ & 7 & $23.33 \%$ \\
\hline AS & 3 & $10.00 \%$ \\
\hline AR & 0 & $00.00 \%$ \\
\hline $\mathrm{MS}+\mathrm{AS}$ & 1 & $3.33 \%$ \\
\hline Congenital & 12 & $28.57 \%$ \\
\hline ASD & 3 & $25.00 \%$ \\
\hline VSD & 3 & $25.00 \%$ \\
\hline Fallot tetralogy & 2 & $16.66 \%$ \\
\hline Primary pulmonary hypertension & 1 & $8.33 \%$ \\
\hline Coarctation of aorta & 2 & $16.66 \%$ \\
\hline Marfan syndrome & 1 & 8.33 \\
\hline
\end{tabular}

In the gravidity of the patients, the gravidity of the women under study; majority of them were primigravidae i.e. $88.09 \%$, followed by second gravidae $(30.95 \%$ and third gravidae 4.76 $\%)$. Regarding the nature of heart lesion, 30 women out of 42 (71.43\%) had rheumatic heart disease of whom 19 (63.33\%) had mitral stenosis as the sole lesion. Combined mitral stenosis and regurgitation occurring in 7 cases, was the second common lesion. In 12 women (28.57\%) the cardiac lesion was congenital in origin of which atrial septal defect (ASD) and ventricular septal defect (VSD) (3 cases each) were most common lesions.

Table 2 shows that out of 30 cases of rheumatic heart disease, only $6(20 \%)$ had surgical correction prior to the present pregnancy whereas 2 patients out of 12 cases of congenital heart disease had prior surgical intervention.

\begin{tabular}{|cccc|}
\hline Type & No. of Cases & Operated & \% \\
Rheumatic & 30 & 6 & $20.00 \%$ \\
Congenital & 12 & 2 & $16.60 \%$ \\
Total & 42 & 8 & $19.57 \%$ \\
\hline \multicolumn{4}{c}{ Table 2. Prior Surgical Operation } \\
\hline
\end{tabular}

New York heart associated classification at the time of admission as shown in Table 5 denotes that $85.71 \%$ of the 
women were NYHA class I, $11.90 \%$ were class II and only 1 patient (2.38\%) was class III at the time of admission.

\begin{tabular}{|ccc|}
\hline Class & No & $\%$ \\
\hline Class I & 36 & $85.71 \%$ \\
Class II & 513 & $11.90 \%$ \\
Class III & 12 & $02.38 \%$ \\
Class IV & 0 & $00.00 \%$ \\
\hline Total & 42 & $100.00 \%$ \\
\hline Table 3. Functional Classifications on Admission (NYHA) \\
\hline
\end{tabular}

Outcome of pregnancy is shown in Table 3. Normal delivery occurred in 8 patients (19.04\%), prophylactic forceps was used to cut short the second stage of labour in 27 cases $(64.28 \%)$ and lower segment caesarean section (LSCS) was needed in 7 cases $(16.66 \%)$.

The indication of LSCS in 5 cases was because of cephalopelvic disproportion (CPD) in 2, nonprogress of labour in 1 , malpresentation in 1, post CS pregnancy in 1 whereas in the rest 2 cases, the indication for LSCS was clinical deterioration of heart disease.

Labour was spontaneous in onset in 33 cases (78.57\%); induction was done in 5 cases $(11.90 \%)$ and indications were all obstetric i.e., intrauterine fetal death (IUFD) in 2 cases, prelabor rupture of membranes (PROM) in 3 cases.

\begin{tabular}{|ccc|}
\hline Methods of Delivery & No. & $\%$ \\
\hline Spontaneous & 33 & $78.57 \%$ \\
\hline Induced & 5 & $11.90 \%$ \\
\hline Table 4 (a). Outcome of Pregnancy, Mode of Onset of Labour \\
\hline *4 cases had elective section. \\
**Reason for Induction: IUFD in 2 cases and PROM in 3 cases. \\
\hline
\end{tabular}

\begin{tabular}{|ccc|}
\hline & No. & $\%$ \\
\hline$<37$ weeks & 12 & $28.57 \%$ \\
$(37-40$ weeks $)$ & 30 & $71.43 \%$ \\
$>40$ weeks & 0 & $0 \%$ \\
\hline Table 4 (b). Outcome of Pregnancy, Gestational Age at Delivery \\
\hline
\end{tabular}

\begin{tabular}{|ccc|}
\hline & No. & $\%$ \\
\hline Normal & 8 & $19.04 \%$ \\
Instrumental (forceps) & 27 & $64.29 \%$ \\
\hline LSCS & 7 & $16.67 \%$ \\
\hline Table 4 (c). Outcome of Pregnancy, Mode of Delivery \\
\hline * Indication for LSCS: Obstetric-5 (CPD-2, Nonprogress of labour-2, Post C.S. in \\
labour-1, Malpresentation-1); Cardiac-2.
\end{tabular}

\begin{tabular}{|ccc|}
\hline Complications & No. & $\%$ \\
\hline $\begin{array}{c}\text { Deterioration (clinical / } \\
\text { echocardiographic) G1 }\end{array}$ & 3 & $7.14 \%$ \\
Cardiac failure G2 & 4 & $9.52 \%$ \\
Pulmonary hypertension & 2 & $4.76 \%$ \\
\hline Table 5 (a). Maternal Complications, Antenatal \\
\hline
\end{tabular}

\begin{tabular}{|ccc|}
\hline Complications & No. & $\%$ \\
\hline Cardiac failure & 6 & $14.28 \%$ \\
Atrial fibrillation & 1 & $2.38 \%$ \\
\hline PPH & 2 & $4.76 \%$ \\
Puerperal sepsis & 2 & $4.76 \%$ \\
\hline Maternal death & 3 & $7.16 \%$ \\
\hline Table 5 (b). Maternal Complications, Intrapartum and Postpartum \\
\hline * Cause of death - Cardiac failure in 2 cases, atrial fibrillation with \\
pulmonary embolism in 1 case
\end{tabular}

Maternal complications are recorded in (Table 5). During antenatal period, 3 patients (7.14\%) had echocardiographic and clinical deterioration of cardiac function, while 4 (9.52\%) developed cardiac failure and $2(4.76 \%)$ had pulmonary hypertension. intrapartum and postpartum cardiac complications were cardiac failure (14.28\%) and atrial fibrillation $(4.70 \%)$ while obstetric complication include postpartum haemorrhage (PPH) and puerperal sepsis in only $4.70 \%$ each. Maternal death occurred in 3 cases (7.14 \%).

As far as the perinatal outcome was concerned, low birth weight ( $47.65 \%)$ and prematurity $(28.57 \%)$ were the major problems in the babies born to these mothers. IUFD occurred in 2 cases ( $4.76 \%$ ). Perinatal mortality was also high i.e. 30.95 $\%$ consisting of 2 cases of IUFD and 11 cases of early neonatal death. Congenital heart disease was recorded in 2 neonates (4.76\%) [Table 6].

\begin{tabular}{|c|c|c|}
\hline Conditions & No. & $\%$ \\
\hline Low birth weight & 20 & $74.61 \%$ \\
\hline Preterm & 12 & $28.57 \%$ \\
\hline IUFD & 2 & $4.76 \%$ \\
\hline $\begin{array}{l}\text { Congenital heart disease in } \\
\text { new born }\end{array}$ & 2 & $4.76 \%$ \\
\hline Low Apgar score $<5$ at birth & 16 & $38.09 \%$ \\
\hline $\begin{array}{c}\text { Perinatal mortality } \\
\text { (stillbirth + neonatal death } \\
\text { in } 1^{\text {st }} \text { week) }\end{array}$ & 13 & $30.95 \%$ \\
\hline \multicolumn{3}{|c|}{ Table 6. Perinatal Outcome } \\
\hline
\end{tabular}

Birth weight record [Table 7] shows a high incidence of low birth weight babies born to these mothers (below $2 \mathrm{~kg}$ $14.28 \%$ and $2-2.4 \mathrm{~kg}-33.35 \%) .17$ babies ( $40.47 \%$ ) were between 2.5 and $3 \mathrm{~kg}$ range and $5(11.90 \%)$ were above $3 \mathrm{~kg}$.

\begin{tabular}{|ccc|}
\hline Wt. & No. & $\%$ \\
$<2 \mathrm{Kg}$. & 6 & $14.28 \%$ \\
$2-2.4 \mathrm{Kg}$. & 14 & $33.34 \%$ \\
$2.5-3 \mathrm{Kg}$. & 17 & $40.47 \%$ \\
$>3 \mathrm{Kg}$. & 5 & $11.91 \%$ \\
\hline \multicolumn{3}{|c}{} \\
\hline
\end{tabular}

\section{DISCUSSION}

The prevalence and incidence of heart disease in pregnancy varies between $4 \%$ in a recent U.K. study ${ }^{9}$ and $1.5 \%$ in a similar study from Srilanka. ${ }^{10}$ The present study does not reflect the true incidence of heart disease in pregnancy as some cases were excluded due to associated complications.

The age and gravidity distribution of study group reflects a preponderance of young primigravidae, the cause of which is obvious as older and multiparous patients with heart disease are discouraged from being pregnant.

The dominant heart lesion in the present study is rheumatic heart disease $(71.43 \%)$ of which mitral stenosis tops the list $(63.3 \%)$. In all the previous series, Rheumatic heart disease is still the commonest and by far the most important is mitral stenosis. ${ }^{10,11}$ However, in a study from London, ${ }^{9}$ only $12 \%$ of 73 pregnant women had rheumatic lesion.

Amongst the congenital heart diseases, VSD, ASD, Fallot's tetralogy and coarctation of aorta were the common lesions found in the present study. No case of patent ductus arteriosus (PDA) was there in the study group. In all the previous series from Dublin (1981),12 Leicester (1985),13 London (1998), ${ }^{13}$ Srilanka (1995), ASD, VSD and PDA accounted for more than $60 \%$ of the cases. 
The surgical correction prior to pregnancy offers better results as far as maternal and neonatal outcome is concerned.9,10,12 However, in the present study only about $19.37 \%$ of the cases had prior surgical correction which is far, and few compared to other parts of the world. None of the cases in present study had surgical correction during pregnancy.

$85.71 \%$ of the parents in the present series had NYHA class I and $11.90 \%$ had class II diseases at the time of admission. 3 patients of class I deteriorated to Class II during antenatal period subsequently. This classification is important in assessing maternal and foetal outcome as maternal mortality varies directly to functional class i.e.4 \% for NHYA class I and II, $6.8 \%$ for class III and IV. Foetal mortality also is greatly influenced by maternal functional class, varying from 0 $\%$ for class I to $30 \%$ for class IV. 14,15

Regarding the outcome of pregnancy and labour, the present study shows that 33 out of 42 women had spontaneous onset of labour. Induction was done in 5 cases and the indication for induction had been obstetric in all the cases i.e. IUFD in 2 cases and PROM in 3.

Induction of labour in heart disease with pregnancy is still a controversial issue. The risks of failed induction and sepsis are the area of concern. However, a recent study by Galia Oran et al in 200416 compared the maternal and perinatal outcome in 2 groups of patients of heart disease - one group comprising of 47 patients who had induction with PGE2 and the other group of 74 patients who had spontaneous onset of labour. No difference in the complication rates in the two groups was observed by the authors and hence it was inferred that induction of labour was a safe procedure in women with heart disease.

7 women (16.66 \%) in the present series needed LSCS. The indication of 2 of them was cardiac i.e. deteriorating cardiac function for which urgent termination was decided upon by LSCS. In the rest 5 cases the indications were obstetric as already described.

Amongst the maternal complications, acute left ventricular failure and pulmonary oedema appeared the most dreaded one, occurring in 6 patients (14.28\%) in immediate postpartum period and all such cases were functional class II or III at the onset of labour. One patient developed atrial fibrillation soon after delivery. None of the patients had infective endocarditis.

Obstetric complications as PPH and puerperal sepsis were not very frequent.

Maternal death occurred in 3 cases (7.14 \%) - 2 cases due to acute left ventricular failure (LVF) and the other one due to pulmonary embolism as a sequel to atrial fibrillation in spite of vigorous management. All these 3 cases were uncorrected rheumatic mitral stenosis with functional class II and III and all 3 deaths were postpartum. Interestingly, none of the congenital heart disease cases had fatality in the present series.

Previous reviews show that maternal mortality is very high in Eisenmenger's Syndrome (30 - $50 \%)^{17}$, primary pulmonary hypertension ${ }^{18}$ (40 - $50 \%$ ) and in Fallot's tetralogy (4 - $20 \%) .{ }^{19}$ One case of primary pulmonary hypertension in the present series however had uneventful recovery.

Although rheumatic heart disease is still an important cause of maternal mortality in developing countries, no death due to the same has been reported in U.K. between 1994 and
$1996 .{ }^{20}$ Rush et al. reported a maternal mortality of $7 \%$ in 450 women with rheumatic heart disease in South Africa. ${ }^{21}$

The major problem as far as perinatal outcome is concerned in the present study has been low birth weight $(47.61 \%)$ and prematurity (28.57\%). These two factors have mainly contributed to a reasonably high perinatal mortality (30.95\%).

Foetal outcome in women with rheumatic heart disease has been found to be good in a previous study by Sugrue D et al. 1981, although the birth weight was low. ${ }^{12}$

In the present series, 2 newborns out of 12 mothers with congenital heart disease had congenital heart lesion similar to the maternal variety. This recurrence pattern has been observed by previous studies at varying incidence of $3-14 \%$ mostly in the left sided outflow obstruction. ${ }^{22,23}$

\section{CONCLUSIONS}

With advances in medical care and surgical approach, the obstetricians should be prepared to manage an increasing number of women with heart disease during pregnancy. A combined multidisciplinary care is essential in managing these cases. Rheumatic heart disease is the major problem in our setting even today. Functional NYHA classification is important as far as maternal and foetal prognosis is concerned. Intensive care during antenatal, intranatal and postnatal period reduces the maternal mortality to a great extent. Although induction of labour is a debatable issue in women with heart disease, recent reports are coming in favour of safe induction in this high-risk group. LSCS is usually indicated for obstetric reason, however, it may have to be done as a method of safe termination in worsening heart condition close to term. Perinatal outcome is not unfavourable in well controlled cases apart from an increased incidence of low birth weight and prematurity.

Data sharing statement provided by the authors is available with the full text of this article at jemds.com.

Financial or other competing interests: None.

Disclosure forms provided by the authors are available with the full text of this article at jemds.com.

\section{REFERENCES}

[1] Siu SC, Sermer M, Colman JM, et al. Prospective multicenter study of pregnancy outcome in women with heart disease. Circulation 2001;104(5):515-21.

[2] McFaul PB, Dorman JC, Lmaki H, et al. Pregnancy complicated by maternal heart disease-a review of 519 women. Br J Obstet Gynaecol 1988;295(9):861-7.

[3] Jindal UN, Dhall GI, Vasistha K, et al. Effect of maternal cardiac disease on perinatal outcome. Aust N Z J Obstet Gynaecol 1988;28(5):113-5.

[4] Avila WS, Rossi EG, Ramires JAF, et al. Pregnancy in patients with heart disease: experience with 1000 cases. Clin Cardiol 2003;26(3):135-42.

[5] Robson SC, Hanter S, Boys RJ, et al. Serial study of factors influencing changes in cardiac output during human pregnancy. Am J Physol 1989;256(4 Pt 2):H1060-5. 
[6] Easterling TR, Benedetti TJ, Schmucker BC, et al. Maternal haemodynamics in normal and preeclamptic pregnancy: a longitudinal study. Obstet Gynaecol 1990;76(6):1061-9.

[7] Siu S, Colman JM. Heart disease and pregnancy. Heart 2001;85(6):710-5.

[8] Lupton M, Oteng-Ntim E, Adiya G, et al. Cardiac disease in pregnancy. Curr Opin Obstet Gynaecol 2002;14(2):13743.

[9] Tan J, De Swiet M, Prevalence of heart disease diagnosed de novo in pregnancy in a West London population. Br J Obstet Gynaecol 1998;105(11):1185-8.

[10] Kaluarachhi A, Seneviratne HR. Heart disease in pregnancy-evaluation of disease pattern and outcome in Srilanka. J Obstet Gynaecol 1995;15(1):9-14.

[11] Szekely P, Turner R, Snaith L. Pregnancy and changing pattern of rheumatic heart disease. Br Heart J 1973;35(12):1293-303.

[12] Sugrue D, Blake S, MacDonald D. Pregnancy complicated by maternal heart disease at the National Maternity Hospital, Dublin, Ireland 1969 to 1978. Am J Obstet Gynaecol 1981;139(1):1-6.

[13] Macnab G, Macafee CAJ. A changing pattern of heart disease associated with pregnancy. J Obstet Gynaecol 1985;5(3):139-47.

[14] Perloff JK. Pregnancy in congenital heart disease the mother and the fetus. In: Perloff JK, Child JS, eds. Congential heart disease in adults. Philadelphia, Pennsylvania: WB Saunders 1991:124-39.
[15] McDaul PB, Dornan JC, Lamki H, et al. Pregnancy complicated by maternal heart disease. A review of 519 women. Br J Obstet Gymaecol 1988;95(9):861-7.

[16] Oron G, Rafael H, Ben-Haroush A, et al. Pregnancy outcome ni women with heart disease undergoing induction of labour. BJOG 2004;111(7):669-75.

[17] Yentis SM, Steer PJ, Plaat F. Eisenmenger's syndrome in pregnancy maternal and fetal mortality in 1990s. Br J Obstet Gynaecol 1998;105(8):921-2.

[18] Sinnenberg RJ. Pulmonary hypertension in pregnancy. South Med J 1980;73(11):1529-31.

[19] Jacoby WJ Jr. Pregnancy with tetralogy and pentalogy of fallot. Am J Cardiol 1964;14:866-73.

[20] Confidential enquiry into maternal death, 1994-1996, Acquired heart disease. DHSS 1998.

[21] Rush RW, Verjans M, Spracklen FH. Incidence of heart disease in pregnancy. A study done at peninsular maternity service hospitals. South Afr Med J 1979;55(20):808-10.

[22] Burn J, Brennan P, Little J, et al. Recurrence risk in offsprings of adults with major heart defects: result from first cohort of British collaborative study. Lancet 1998;351(9099):311-6.

[23] Nora JJ, Nora AH. Maternal transmission of congenital heart diseases: new recurrence risk figures and the questions of cytoplasmic inheritance and vulnerability to teratogens. Am J Candiol 1987;59(5):459-63. 